\title{
Green Polyurethane Nanocomposites from Soy Polyol and Bacterial Nanocellulose
}

M. Ozgur Seydibeyoglu ${ }^{1}$, Manjusri Misra ${ }^{1,2,}{ }^{*}$, Amar Mohanty $^{1,2}$, Jonny J. Blaker ${ }^{3}$, Koon-Yang Lee $^{3}$, Alexander Bismarck ${ }^{3}$, Mohammad Kazemizadeh ${ }^{4}$

1. Bioproducts Discovery \& Development Centre (BDDC), Department of Plant Agriculture, University of Guelph, Guelph, Ontario, N1G 2W1, Canada

2. School of Engineering, University of Guelph, Ontario, N1G 2W1, Canada

3. Polymer and Composite Engineering (PaCE) Group, Department of Chemical Engineering, Imperial College London, South Kensington Campus, London SW7 AZ, UK

4. Arkema Inc., 157 Highway Avenue North, Blooming Prairie, MN 55917, USA

*Corresponding author: mmisra@uoguelph.ca

Phone:+1-519-824-4120 x. 56766

Fax: +1-519-763-8933 


\begin{abstract}
With increased environmental concerns, fluctuations in oil prices and dependency on oil, there has been an emergence in the use of biobased polyurethanes prepared with polyols derived from plant oils, such as soybean oil. In this study, novel polyurethane materials were synthesized using polyols obtained from soybean oils. The polyurethanes were produced by reacting the polyols with polymeric isocyanate with an isocyanate index of 100 at $150{ }^{\circ} \mathrm{C}$ for two hours for complete curing. The mechanical properties of this biobased polyurethane were improved by incorporating novel nano size cellulose materials produced from bacteria. The source of the bacterial cellulose nano-fibrils was a commercially available food product nata-de-coco. A fine dispersion of the nanocellulose fibrils in biobased polyurethane matrix was achieved using a high speed homogenizer at 30,000 rpm, which was observed using field emission transmission electron microscopy and scanning probe microscopy. The average diameter size of the cellulose fiberils were determined to be $22 \pm 5 \mathrm{~nm}$ by scanning probe microscopy observations. The flexural strength and flexural strength was improved even at $0.125 \mathrm{wt} \%$ bacterial cellulose concentration and the optimum nanocomposite was obtained with $0.25 \mathrm{wt} \%$ concentration due to good interaction of isocyanates and the cellulose. Dynamic mechanical analyses were consistent with the flexural test results in terms of modulus. The transparent thick nanocomposite samples shows one additional advantage of the nanocomposite technology.
\end{abstract}




\section{Introduction}

Polyurethane materials attract much attention due to their versatile applications with a wide variety of polyols and isocyanates available to synthesize polyurethanes. The polyurethane was first discovered in the 1940s and still there is an extensive research on this type of polymer to improve the properties and to synthesize new materials with new functional groups. Polyurethanes are currently used as films, foams, and rigid materials ${ }^{1-3}$. The main application areas are mainly construction materials and in the automotive industry in the form of foams and rigid applications ${ }^{4}$. This family of polymers is also widely used in coating, and elastomers ${ }^{5-7}$. Furthermore polyurethanes are used for some biomedical applications as well ${ }^{8}$.

With the increased environmental concerns and fluctuations in oil prices, interest in biobased materials is rising. Plants offer alternative chemicals to petroleum based chemicals. Plant based chemicals are renewable and they are biodegradable as a consequence of their biological properties. Extracted plant oils have been used in polymer synthesis ${ }^{9,10}$. Castor oil is commonly used for the synthesis of polyurethanes due to high hydroxyl content ${ }^{9}$.

In recent years, soybean oils are being converted to soy polyols by introducing hydroxyl groups

to the structure to be reactive for polyurethane synthesis ${ }^{11-13}$. Soy polyols with different functional groups and different hydroxyl content are also being produced. Soy polyols offer new polyurethane formulations, but for commercial applications soy polyols are not fully utilized in the polyurethane formulations due to reduction in mechanical properties compared with the 
petrochemical polyols ${ }^{14}$. There have been studies to optimize the polyurethane synthesis using soy polyols with different hydroxyl numbers ${ }^{15,16}$, and different amounts of isocyanates ${ }^{17}$.

The properties of soy polyol based polyurethanes can be improved with certain reinforcing phases. There have been studies showing the improved properties of polyurethane with the use of glass fibers and natural fibers ${ }^{14,18,19}$. Among the reinforcing materials, cellulose fibers, especially nano cellulose fibers, are attracting much attention ${ }^{20}$.

Cellulose can be obtained from a vast range of sources, including plant, tunicates and certain strains of bacteria. Cellulose nanofibrils prepared from tunicates and cellulose produced via bacteria inherently have dimensions in the nano-scale. Cellulose nano-whiskers can be obtained from all the above sources, most commonly through acid hydrolysis of the cellulose fibers ${ }^{21}$. Detailed investigations on the whisker production are still under extensive research especially from different plant resources ${ }^{22}$. Microfibrillated cellulose is generally obtained by the defibrillation of the cellulose by the use of high pressure homogenizers ${ }^{7,23}$.

Bacterial cellulose is obtained via biotechnological routes ${ }^{24-26}$ and is commonly produced from the Acetobacter xylinum bacteria ${ }^{27}$. It has the identical structure compared to plant based cellulose $^{24}$. It was reported that it has elastic modulus as high as $114 \mathrm{GPa}^{28}$. Bacterial cellulose can be regarded as a pure form of cellulose in comparison with those from plant sources, in order to obtain cellulose from plant resources, the cellulose should be separated from lignin, hemicellulose, pectin and waxes in the plant.

In this study, we hypothesize that bacterial cellulose nano-fibrils can reinforce the soy polyol based polyurethanes significantly and this can lead to novel polyurethane products with enhanced properties. Currently soy polyol is partially used in the polyurethane industry due to 
the lower mechanical properties. The pure form of cellulose at the nanoscale can improve the properties of soy polyol based polyurethane. We attempt to improve the mechanical properties of soy polyol based polyurethane by incorporating bacterial cellulose nano-fibrils .

\section{Experimental}

Materials. Soy polyol was obtained from Arkema Inc. with a hydroxyl number of $166 \mathrm{~g}$ $\mathrm{KOH} / \mathrm{mg}, 0.42$ acid value, and $1144 \mathrm{cps}$ viscosity. Soy polyol was specially produced for this research and the polyol synthesis conditions are proprietary. The polyurethane synthesis was conducted with a commercial isocyanate (polymeric diphenyl methane diisocyanate (pMDI)) obtained as a gift from Huntsman Chemicals under the trade name Rubinate M. pMDI had a functionality of 2.7, and \% NCO of 31.2. Dibutyl tin dilaurate (DABCO T12) catalyst was obtained from Air Products. The bacterial cellulose nano-fibrils were obtained from nata-decoco, a commercially available product, $\mathrm{CHAOKOH}$, coconut gel in syrup (Thep. Padung Porn Coconut Co. Ltd. Bangkok, Thailand); the purification and extraction procedure is detailed below.

Extraction and purification of cellulose nano-fibrils. Bacterial cellulose was extracted from nata-de-coco in batches of five jars (of net weight $500 \mathrm{~g}$ each). For each batch, the coconut gel content was rinsed three times with $5 \mathrm{~L}$ of de-ionized water and blended for 1 min using a laboratory blender (Waring Blender LB20EG, Christison Particle Technologies, Gateshead, UK). The blended bacterial cellulose was then homogenized at 20,000 rpm in $5 \mathrm{~L}$ of water for $2 \mathrm{~min}$ using a homogenizer (Polytron PT 10-35 GT, Kinematica, $\mathrm{CH}$ ) and centrifuged at 14,000 g to remove excess water and heated in a $0.1 \mathrm{M} \mathrm{NaOH}$ solution at $80{ }^{\circ} \mathrm{C}$ for 20 min to remove any remaining microorganisms and soluble polysaccharides. The purified bacterial cellulose was then 
successively centrifuged and homogenized to neutral $\mathrm{pH}$ using de-ionsed water. A dry cellulose nano-fibril product was obtained by freeze-drying as follows. The cellulose dispersion was adjusted to a concentration of $4 \mathrm{mg} / \mathrm{ml}$ in water, which was then poured into polyethylene beakers in volumes of $250 \mathrm{ml}$ which were then frozen in liquid nitrogen, after $2 \mathrm{~h}$ the frozen product was transferred to freeze-dryer (Edwards Modulyo freeze dryer, West Sussex UK) and the resultant freeze-dried nano-cellulose fibrils retained for later modification and inclusion in composite production.

Synthesizing Polyurethane and Polyurethane Nanocomposites. The polyurethane reactions were carried out with an isocyanate index of 1.00 with a small amount of catalyst in the reaction system $(0.2 \mathrm{wt} \%)$. The polyol, catalyst and pMDI were mixed for 2 minutes and the mixture was poured into molds and the polymer was cured for 2 hours at $150{ }^{\circ} \mathrm{C}$ using compression molding creating $3.5 \mathrm{~mm}$ thick polymer sheets.

The nanocomposites of polyurethane were prepared using the following steps. Firstly, bacterial cellulose was dispersed in the soy polyol manually and then further dispersed in the polyol with the use of a high speed homogenizer (Fisher Scientific PowerGen Model 125) at $30000 \mathrm{rpm}$ in an effort to improve homogeneous distribution of the nano-fibrils. The homogenized product was then placed in vacuum oven at room temperature for 3 hours to remove any air bubbles that formed during the homogenization process. After this de-gassing step, the catalyst ( $0.2 \mathrm{wt} \%)$ and pMDI with isocyanate index of 1.00 was added, mixed for 2 minutes and the nanocomposite poured into the square molds with dimensions of $71 * 50 * 3.5 \mathrm{~mm}$ and cured for 2 hours at $150^{\circ} \mathrm{C}$ with compression molding with a pressure of 50 psi. The preparation steps are shown 
schematically in Figure 1a. The various weight fractions investigated (up to a maximum of 0.375 wt $\%$ nano-cellulose fibrils) and their respective sample codes are summarized in Table 1.

\section{Characterization}

Fourier Transform Infrared Spectroscopy (FTIR)

FTIR measurements were conducted with Thermo Scientific Nicolet 6700, with the ATR attachment of the instrument. The number of scans was 32 for each sample with a resolution of 4.

\section{Mechanical Testing}

Flexural strength was measured with Instron (3382) testing machine according to ASTM D790. The flexural samples sizes were $10 * 60 * 3.5 \mathrm{~mm}$ and the speed of testing was $14.08 \mathrm{~mm} / \mathrm{min}$. Izod notched impact strength was measured with Testing Machine Inc. (TMI) according to ASTM D256. The sample sizes were same as flexural testing. The pendulum used for the test was $0.5 * 0.5 \mathrm{ft} . \mathrm{lbs}$.

Dynamic Mechanical Analysis (DMA)

DMAQ800 from TA instruments was used to measure the storage modulus and tan delta of polyurethane and nanocomposites in three point bending mode. The samples were heated from $50^{\circ} \mathrm{C}$ to $100^{\circ} \mathrm{C}$ and a rate of $3{ }^{\circ} \mathrm{C} / \mathrm{min}$ with amplitude of $15 \mu \mathrm{m}$ and a frequency of $1 \mathrm{~Hz}$.

Transmission Electron Microscopy (TEM)

The images were taken at $200 \mathrm{kV}$ on the FEI Tecnai G2 F20 TEM with a Gatan 4k digital camera using the DigitalMicrograph software. The samples were sectioned $(100 \mathrm{~nm})$ mounted on 
300 mesh carbon grids and post stained with aqueous $2 \%$ Uranyl acetate $(10 \mathrm{~min})$ and Lead Citrate (4 min) then $10 \%$ Uranyl acetate in methanol for $12 \mathrm{~min}$.

Scanning Probe Microscopy (SPM)

Agilent 5500 scanning probe microscope with Olympus IX71 inverted optical microscope was used to observe the nano size bacterial cellulose fibers. Silicon nitride tip with spring constant of $0.6 \mathrm{~N} / \mathrm{m}$ was used for the observations.

\section{Results and Discussion}

Fourier Transform Infrared Spectroscopy. The synthesis conditions for the polyurethane were optimized using the FTIR analysis. The FTIR peak, at $2271 \mathrm{~cm}^{-1}$ is very important for the polyurethane synthesis. This corresponds to free, unreacted isocyanate peak in the polyurethane structure. There was no free isocyanate peak observed at $2271 \mathrm{~cm}^{-1}$ showing successful polyurethane synthesis. The specific peaks are shown in the Figure 2 for the polyurethane. These peaks are $2900 \mathrm{~cm}^{-1}, 1690 \mathrm{~cm}^{-1}$, and $1376 \mathrm{~cm}^{-1}$ corresponding to $\mathrm{C}-\mathrm{H}$ stretching, $\mathrm{C}=\mathrm{O}$ stretching, and C-N bonding, respectively ${ }^{30}$.

In Figure 2, FTIR spectra of the polyurethane nanocellulose composites are also shown. The FTIR peaks show that nanocomposites were successfully synthesized without any isocyanate peak at $2271 \mathrm{~cm}^{-1}$. The cellulose peaks could not be observed as the concentration of the cellulose in the polyurethane matrix did not exceed $0.375 \mathrm{wt} \%$. It is reported that for polyurethane lignin blend casted as film, the polyurethane FTIR peaks were not altered much and lignin peaks were not observed even at $9 \mathrm{wt} \%$ lignin concentrations ${ }^{31}$. For a nanocomposite at $0.375 \mathrm{wt} \%$, it is not possible to separate specific peaks of cellulose peaks. The amount of 
cellulose is so low in concentration that it can not be easily detected. This observation shows the importance of the nanocomposites as the properties of the matrix polymer changes significantly with a very small amount of the nano filler.

Flexural Test Results Flexural testing was applied for the materials under investigation due to the application areas of the polyurethanes as they are mainly subjected to bending and flexural loads. The measurements and properties of the neat polyurethane and the nanocomposites are summarized in Table 2. It was observed that the nano cellulose, even at very low loadings (less than $0.5 \mathrm{wt} \%$ ) percentages are very effective in reinforcing neat polyurethane. The fine dispersion of the nanocellulose fibrils with the polyurethane was observed with the transmission electron microscopy studies and atomic force microscopy studies. The increase in the strength values was $100 \%$ for $0.250 \mathrm{wt} \%$ nanocellulose and the increase in the modulus values was $50 \%$ for $0.375 \mathrm{wt} \%$ for the nanocellulose addition. The strength and modulus values very leveling off at $0.250 \mathrm{wt} \%$ and $0.375 \mathrm{wt} \%$ due to saturation of cellulose dispersion at these concentrations. The electron microscopy studies also confirm that cellulose dispersions are similar and properties are quite similar. The cellulose dispersion reaches a maximum. During the experiments $0.5 \mathrm{wt} \%$ and higher concentrations could not be prepared due to agglomeration. This leveling was reflected in the flexural test data as well.

Cellulose and lignocellulosic materials are quite well known for their hydrophilic properties ${ }^{24,32-}$ ${ }^{34}$. For example, Blaker et al. ${ }^{24}$ measured the water contact angle in air of bacterial cellulose at $11^{\circ}$. They modified cellulose to be hydrophobic with silane coupling agents to create good nanocomposite foams via Pickering emulsion templating ${ }^{24}$. By tailoring the hydrophobicity of bacterial cellulose nano-fibrils by esterification with organic acids, polylactide matrix nano- 
fibrillated bacterial cellulose composites with improved properties have been produced ${ }^{35}$. Lu et al. ${ }^{34}$ also modified the hydrophilicity of the microfibrillated cellulose to be compatible with the epoxy resins with silane and titanate coupling agents observing that titanate coupling agents improved the properties. The incompatibility of the cellulosic fibers with the thermoplastic resins has been one of the obstacles of the natural fiber composites. A recent study on nanocellulose composites with polypropylene has shown that the surface modification was needed for the cellulose whiskers to prepare successful nanocomposites ${ }^{33}$. So in this study, polyurethane was used as the matrix polymer which can be regarded as a more hydrophilic material due the prevalence of hydroxyl groups obtained from the polyols during the synthesis. Polyurethanes are generally hydrophilic materials. In one study, the polyurethane water contact angle was reported by Seydibeyoglu et al. ${ }^{3}$ as $67^{\circ}$. The good compatibility of the cellulose with the polyurethane helps to improve the properties of the neat polyurethane matrix significantly. Furthermore, an improved interaction between the polyurethane and the cellulose arises due to the isocyanate groups in the polyurethane. The isocyanate has been used as surface modifier for the cellulosic based composite materials since $1989^{36}$. The bacterial cellulose and the isocyanates can also react in this nanocomposite preparation system but the content of the bacterial cellulose (less than $0.5 \mathrm{wt} \%$ ) is so low that this reaction would not contribute significantly.

Another important finding of the study was that the bacterial cellulose could not be incorporated to the polyurethane matrix more than $0.5 \mathrm{wt} \%$. During the preparation of the samples, mechanical properties and the TEM images confirmed this observation. When the cellulose was dispersed with the homogenizer in the polyol shown in Figure 1, the bacterial cellulose could not be dispersed above $0.5 \mathrm{wt} \%$ as the cellulose was thickening the polyol and the cellulose fibrils agglomerated; nanocomposites at this higher loading were therefore not prepared. Different 
forms of cellulose have been used as a viscosity modifier for many years and recently the viscosity change with cellulose addition was shown by Kahng et al. ${ }^{37}$ The nano size effect becomes very effective by the dispersion of the nanosized cellulose fibers in the polyol.

Furthermore the results are compared with the theoretical model of "Rule of Mixtures" which is the fundamental theory for composites especially for long fiber composites. The rule of mixtures is stated in the following equation,

$\mathrm{E}_{\mathrm{c}}=\mathrm{E}_{\mathrm{m}} * \mathrm{~V}_{\mathrm{m}}+\mathrm{E}_{\mathrm{f}} * \mathrm{~V}_{\mathrm{f}}$

where $\mathrm{E}_{\mathrm{c}}$ is the modulus value for the composite, $\mathrm{E}_{\mathrm{m}}$ is the modulus value of the matrix polymer, $\mathrm{V}_{\mathrm{m}}$ is the volume fraction of the matrix polymer, $\mathrm{E}_{\mathrm{f}}$ is the modulus value for the fiber and $\mathrm{V}_{\mathrm{f}}$ is the volume fraction of the fiber.

In the calculations for this study, the weight fractions are converted to volume fractions and volume fractions used are $0.1,0.2$, and 0.3 corresponding to $0.125,0.250$, and $0.375 \mathrm{wt} \%$ respectively. In Figure $3 a$ and $3 b$, the experimental data and the calculated data are plotted. In Figure 3a, the experimental data and the theoretical model data are plotted with the modulus value of the bacterial cellulose taken as $114 \mathrm{GPa}$ based on previous published data ${ }^{28}$. In Figure $3 \mathrm{~b}$, this time the experimental data and the theoretical model is plotted but this time the modulus value of the bacterial cellulose is taken as $12.9 \mathrm{GPa}$. This value is calculated value from back calculations of the 0.2 volume $\%$ nanocomposites during this study.

Figure 3a shows that the experimental values are in a good trend but the modulus value for the bacterial cellulose taken from the literature did not fit into the experimental data. This can be attributed to the model adopted to long fibers whereas in this study, the bacterial cellulose as 
shown by TEM images are short fibers as they are broken during the homogenization process for the fine dispersion. Thus the orientation of the short fibers is much different than that for long fibers. The second factor is that the bacterial cellulose would be modified during the polyurethane synthesis being exposed to chemical interactions of the polyol and the isocyanates thereby reducing the strength of the bacterial cellulose. The third factor may be the interface between the polyurethane and the bacterial cellulose. Though the strength values increase, better interface could have improved the adhesion yielding a higher modulus value for the bacterial cellulose.

The rule of mixtures can be rewritten with the correction factor, $\mathrm{k}$ which corresponds to the difference in the modulus values due to reasons explained previously. Rule of mixture is generally used for long fiber composites and the correction factor is generally used to adopt the rule of mixture to short fiber composites.

$\mathrm{E}_{\mathrm{c}}=\mathrm{E}_{\mathrm{m}} * \mathrm{~V}_{\mathrm{m}}+\mathrm{k}^{*} \mathrm{E}_{\mathrm{f}} * \mathrm{~V}_{\mathrm{f}}$

From these calculations $\mathrm{k}$ value can be calculated as $12.9 / 114=0.113$.

So after these observations, the curves were plotted by taking the bacterial cellulose modulus value as 12.9 MPa. Figure $3 \mathrm{~b}$ shows the experimental data and theoretical model, overlaid. The results are very promising showing almost the same trend. The rule of mixtures could be used for the bacterial cellulose nanocomposites with the corrected modulus values showing the linear trend. Even the modulus value of bacterial cellulose obtained is much lower than theoretical values, it is high compared to many polymeric materials and it shows that the nano cellulose has a big potential for many different applications. 
The reinforcement of the soy polyol based polyurethanes was done previously with the use of the glass fibers and natural fibers ${ }^{14,18,19}$. They observed the load transfer from the polyurethane matrix to the fibers which is the essential mechanism for the composite materials. By this study, with small amounts of nanocomposites similar reinforcements could be observed with less than $0.5 \mathrm{wt} \%$. Latere Dwan'Isa et al. ${ }^{18}$ observed that soy polyol based polyurethane tensile strength was improved from $0.7 \mathrm{MPa}$ to $1.1 \mathrm{MPa}$ with $30 \mathrm{wt} \%$ glass fiber. So with the use of the nanocellulose at a loading of $0.250 \mathrm{wt} \%$ similar improvements could be achieved and this will help to improve the properties of soy polyol based polymers.

Impact Strength. To the best of our knowledge, this is the first report in literature of the measurement of the impact strength of nanocomposites based on nanocellulose. The results for this study are summarized in Table 2. For the natural fiber composites, the natural fibers generally decrease the impact strength of the polymer matrices ${ }^{38,39}$. The impact strength is related to the crack propagation through the polymer matrix and the energy absorbing capacity of the polymer during the sudden impact loadings ${ }^{18}$. For the polyurethane matrices, the impact strength is high having a value of $82.76 \mathrm{~J} / \mathrm{m}$. The impact strength of the neat polyurethane was improved with the glass fibers with a similar polymer matrix due to the high strength properties and energy absorbing mechanisms of the glass fibers ${ }^{18}$. In this study, it was observed that the presence of bacterial cellulose acted to decrease the impact strength of the composite, as has been found for other natural fiber reinforced systems $s^{38,39}$. Whilst the polyurethane matrix is a tough, rubbery polymer with high energy absorption, it was not possible to improve the crack propagation with the use of nanocellulose due to the low impact properties of cellulosic fiber properties. 
Dynamic Mechanical Analysis. The modulus values were measured using dynamic mechanical analysis at elevated temperatures to observe the changes of the storage modulus values with changes in temperature. The observations were consistent with the flexural test results. The storage modulus values increased as the nano cellulose content increased (Figure 4a). The increasing trend was similar to the modulus values obtained flexural test results and the values were also in the same range of 100-150 MPa. The polyurethane modulus was measured as 100.1 MPa at room temperature by DMA.

With the use of polyol with a hydroxyl number around $160 \mathrm{mg} \mathrm{KOH} / \mathrm{g}$, the polyurethane becomes flexible or semi-flexible but not rigid ${ }^{18}$. To achieve rigid polyurethane polyol with $\mathrm{OH}$ number of 250 or higher $\mathrm{mg} \mathrm{KOH} / \mathrm{g}$ is needed ${ }^{18}$. The flexibility of the polyurethane decreases as the nano cellulose is incorporated to the system. This is reflected in the modulus values as well. The improvement of the modulus values were observed throughout the entire temperature scan.

The representative tan delta curve for the polyurethane is shown in Figure $4 \mathrm{~b} . \mathrm{T}_{\mathrm{g}}$ was measured from the onset temperature and peak of the tan delta curve as $-1.15^{\circ} \mathrm{C}$ and $37.73^{\circ} \mathrm{C}$ respectively. The onset value for determination of $T_{g}$ is more appropriate as the polymer chains start to soften and segmental mobility begins. Figure $4 \mathrm{c}$ shows the combined tan delta curves for PU and nanocomposites. As the bacterial cellulose is introduced into the polyurethane, the height of tan delta curves is reduced due to higher modulus values as tan delta is the ratio of loss modulus over storage modulus. The increase in the storage modulus results in decrease of the tan delta curves. There is a also shift in $T_{g}$ values to higher values due to good interaction of the polyurethane and bacterial cellulose being both phases hydrophilic. The $\mathrm{T}_{\mathrm{g}}$ value increases as the bonding between 
the polyurethane and the cellulose makes the nanocomposite much more stiff resulting in higher glass transition temperatures.

Transmission Electron Microscopy and Visual Investigations of Samples. Obtaining images was problematic initially but with appropriate staining methodologies developed it was possible to observe the bacterial cellulose dispersions. The repeatability of the sample preparation techniques was confirmed by performing the experiment twice. Figure $5 \mathrm{a}$, and $5 \mathrm{~b}$ show the bacterial cellulose dispersions at different magnifications. Excellent distribution of bacterial cellulose nano-fibrils in the polyurethane matrix is evidenced by the images. This is encouraging as it is generally very difficult to achieve good dispersion when producing nanocomposites. The fibrils are highlighted in the red circles (Figures $5 \mathrm{a}$ and $5 \mathrm{~b}$ ). The fine dispersion of the bacterial cellulose fibrils provides the increase in the flexural strength. The diameter of the bacterial cellulose fibrils are in the range of $20-30 \mathrm{~nm}$ which is consistent with the literature ${ }^{41-43}$. Tokoh et al. ${ }^{42}$ and Astley et al. ${ }^{43}$ estimated the thickness of bacterial cellulose around $30-50 \mathrm{~nm}$. The otherwise fine dispersion of the nano cellulose fibrils in the polyurethane matrix was detrimentally affected at loadings above $0.375 \mathrm{wt} \%$, as the fibrils tended to agglomerate, at these loadings good polyurethane nanocomposites could not be produced. Figure 5c shows the polyurethane nanocomposites for $0.250 \mathrm{wt} \%$ nano cellulose dispersion (the scale basr is $200 \mathrm{~nm}$ ). The image can be compared with the Figure 5a and it can be easily concluded that the cellulose content is much higher than $0.125 \mathrm{wt} \%$ nanocomposites which is also reflected in the mechanical properties.

Figure $5 \mathrm{~d}$ shows the polyurethane nanocomposites with $0.375 \mathrm{wt} \%$ nanocellulose. The fine dispersion was obtained. The images were similar to the images of PUBC250 which was very 
important as the mechanical properties (flexural strength) were also leveling at these concentrations, corroborated by the TEM observations here.

Photographic images of the samples are presented in Figure 6, evidencing that all the samples including neat polyurethane and nanocomposites are transparent; one of the most important aspects of the nanocomposites ${ }^{44,45}$. At certain thicknesses and if the filler is well dispersed, transmission of light is not affected and not scattered so it passes through the material and that is why the nanocomposites with less than $100 \mathrm{~nm}$ thick fillers are transparent ${ }^{45}$. The transparency was slightly reduced with bacterial cellulose compared to neat polyurethane but transparency of the nanocomposites was in the same range. The transparency of the products was observed with thick polymer samples of $35 \mathrm{~mm}$, which is very novel. This observations is different from transparent nanocomposite materials based on films ${ }^{44,45}$.

Scanning Probe Microscopy (SPM) Investigations. This study was conducted to observe the fiber structure at the nanoscale, resolved from 3D images obtained with the scanning probe microscopy. The images confirmed the TEM images obtained. The nano fibers at the range of the 20-30 nm were observed. Figure 7a shows the topography image of PUBC125. The nano fibers are shown with arrows. With the software, the average thickness of the cellulose nano fibers could be determined. The average thickness was resolved to $22.2 \pm 5.3 \mathrm{~nm}$ (average based on 100 measurements), which shows the fine dispersion of the nano cellulose in the polyurethane.

\section{Conclusions}

Bacterial cellulose nano-fibrils were used to reinforce polyurethane, which itself was synthesized from $100 \%$ soy polyol. Nanocomposites with finely dispersed cellulose fibrils in the 
polyurethane matrix were obtained. The properties of the polyurethane nanocomposites were investigated with Fourier transform infra-red spectra analysis, mechanical tests, thermal tests and microscopy techniques. It was observed that fine dispersion of the bacterial cellulose was achieved and as a result of both flexural strength and modulus improved over the unfilled samples by $100 \%$ and $50 \%$, respectively. These significant reinforcements were achieved with less than $0.5 \mathrm{wt} \%$ bacterial cellulose in the polyurethane structure showing the importance of nanocomposites. The optical properties of thick sections of these nanocomposites were preserved.

\section{Acknowledgements}

MOS and AKM are thankful to the Ministry of Research and Innovation of Ontario, Canada for the post-doctoral research fellowship. Partial financial supports from NSERC-Discovery grant program individual (Mohanty) and The Ontario Ministry of Agriculture, Food and Rural Affairs (OMAFRA) and the University of Guelph-2009 Bioeconomy-Industrial Uses Research Program are greatly appreciated. Prof. John Dutcher and his group are acknowledged for the use of SPM facilities. Arkema is greatly acknowledged for the donation of novel soy based biopolyols for this research. AB and KYL acknowledge funding provided by the UK Engineering and Physical Science Research Council (EPSRC) (EP/F032005/1). JJB and AB acknowledge funding from the Challenging Engineering Programme of the EPSRC (EP/E007538/1).

\section{References}


1. Rehab, A.; Salahuddin, N.; Mater. Sci. Eng. A 2005, 399, 368-76.

2. Gorrasi, G.; Tortora, M.; Vittoria, V.; J. Polym. Sci. Part B: Polym. Phys. 2005, 43, $2454-2467$.

3. Seydibeyoglu, M.O.; Isci, S.; Gungor, N.; Ece, O.I.; Guner, F.S.; J. Appl. Polym. Sci. 2010, 116, 832-837.

4. Oertel, G. Polyurethane Handbook, Hanser Gardner Publications, 1994.

5. Seydibeyoglu, M.O.; Oksman, K.; Compos. Sci. Technol. 2008, 68, 908-914.

6. Petrovic, Z.S.; Ferguson, J.; Prog. Polym. Sci. 1991, 16, 695-836.

7. Y1ld1z, B.; Seydibeyoglu, M.O.; Guner, F.S.; Polym. Degrad. Stab. 2009, 94, 1072-1075.

8. Lambda, N.M.K.; Woodhouse, K.A.; Cooper, S.L.; Polyurethanes in Biomedical Applications, CRC Press, 1997.

9. Sharma,V.; Kundu, P.P.; Prog. Polym. Sci. 2008, 33, 1199-1215.

10. Güner, F.S.; Yağc1, Y.; Erciyes, A.T.; Prog. Polym. Sci. 2006, 31, 633-670.

11. Kiatsimkul, P.P.; Suppes, G.J.; Sutterlin, W.R.; Ind. Crops Prod. 2007, 25, 202-209.

12. Kiatsimkul, P.P.; Suppes, G.J.; Hsieh, F.H.; Lozada, Z.; Tu, Y.C.; Ind. Crops Prod. 2008, $27,257-264$

13. Guo, A.; Demydov, D.; Zhang, W.; Petrovic, Z.S.; J. Polym. Environ. 2002, 10, 49-52.

14. Husic, S.; Javni, I.; Petrovic, Z.S.; Compos. Sci. Technol. 2005, 65, 19-25.

15. Latere Dwan'Isa, J.P.; Mohanty, A.K.; Misra, M.; Drzal, L.T.; Kazemizadeh, M.; J. Polym. Environ. 2003, 11,161-168.

16. Ferrer, M.C.C.; Babb, D.; Ryan, A.J.; Polymer, 2008, 49, 3279-3287.

17. Tu, Y.C.; Fan, H.; Suppes, G. J.; Hsieh, F.H.; J. Appl. Polym. Sci. 2009, 114, 2577-2583. 
18. Latere Dwan'Isa, J.P.; Mohanty, A.K.; Misra, M.; Drzal, L.T.; Kazemizadeh, M.; J. Mater. Sci. 2004, 39, 2081-2087.

19. Latere Dwan'Isa, J.P.; Mohanty, A.K.; Misra, M.; Drzal, L.T.; Kazemizadeh, M.; J. Mater. Sci. 2004, 39, 1887-1890.

20. Dufresne, A. Cellulose based composites and nanocomposites Monomers, polymers and composites from renewable resources. Elsevier Academic Press, 2008; p.401.

21. Bondeson, D.; Mathew, A.; Oksman, K.; Cellulose 2006, 13, 171-180.

22. Chen, Y.; Liu, C.; Chang, P. R.; Cao, X.; Anderson, D. P.; Carbohyd. Polym. 2009, 76, $607-615$.

23. Nakagaito, A.N.; Fujimura, A.; Sakai, T.; Hama, Y.; Yano, H.; Compos. Sci. Technol. 2009, 69, 1293-1297.

24. Blaker, J.J.; Lee, K.Y.; Li, X.; Menner, A.; Bismarck, A.; Green Chem. 2009, 11, 13211326.

25. Lee, K.Y.; Blaker, J.J.; Bismarck, A.; Compos. Sci. Technol. 2009, 69, 2724-2733

26. Gindl, W.; Keckes, J.; Compos. Sci. Technol. 2004, 64, 2407-2413.

27. Juntaro, J.; Pommet, M.; Kalinka, G.; Mantalaris, A.; Shaffer, M.S.P., Bismarck, A.; Adv. Mater. 2008, 20, 3122-3126.

28. Hsieh, Y.C.; Yano, H.; Nogi, M., Eichhorn, S. J.; Cellulose 2008, 15, 507-513.

29. Toyosaki, H.; Naritomi, T.; Seto, A.; Matsuoka, M.; Tsuchida, T.; Yoshinaga, F. Biosci. Biotech. Biochem. 1996, 59, 1498-1502.

30. Mishra, A.K.; Chattopadhyay, D.K.; Sreedhar, B.; Raju, K.V.S.N.; Prog. Org. Coat. 2006, 55, 231-243. 
31. Ciobanu, C.; Ungureanu, M.; Ignat, L.; Ungureanu, D.; Popa, V.I.; Ind. Crops Prod. 2004, 20, 231-241.

32. Jiang, L.; Morelius, E.; Zhang, J.; Wolcott, M.; J. Compos. Mater. 2008, 42, 2629-2645.

33. Ljungberg, N.; Cavaille, J.Y.; Heux, L.; Polymer 2006, 47, 6285-6292.

34. Lu, J.; Askeland, P.; Drzal, L.T.; Polymer 2008, 49, 1285-1296.

35. Lee, K.Y.; Blaker, J.J.; Bismarck, A. Compos. Sci. Technol. 2009, 69, 2724-2733.

36. Raj, R.G.; Kokta, B.V.; Maldas, D.; Danealt, C.; J. Appl. Polym. Sci. 1989, 7, 1089-1103.

37. Kahng, G.G.; Lim, S.H.; Yun, H.D.; Seo, W.T.; Biotechnol. Bioprocess Eng. 2001, 6, 112-116.

38. Bledzki, A. K.; Faruk, O.; Compos. Sci. Technol. 2004, 64, 693-700.

39. Keller, A.; Compos. Sci. Technol. 2003, 63, 1307-1316.

40. Senthilkumar, N.; Raghavan, A.; Nasar, A. S.; Macromol. Chem. Phys. 2005, 206, 24902500.

41. Iguchi, M.; Yamanaka, S.; Budhiono, A.; J. Mater. Sci. 2000, 35, 261-270.

42. Tokoh, C.; Takabe, K.; Fujita, M.; Saiki, H.; Cellulose 1998, 5, 249-261.

43. Astley, O.M.; Chanliaud, E.; Donald, A.M.; Gidley, M.J.; Int. J. Biol. Macromol. 2001, 29, 193-202.

44. Stelzig, B.S.H.; Klapper, M.; Müllen, K.; Adv. Mater. 2008, 20, 929-932.

45. Kim, Y.; Jung, R.; Kim, H.S.; Jin, H.J. Curr. Appl Phys. 2009, 9 S69-S71.

Figure Captions 
Figure 1a: General Scheme for the Preparation of Polyurethane-Bacterial Cellulose Nanocomposites

Figure 1b: Model for the Fine Dispersion of Bacterial Cellulose in Biobased Polyurethane

Figure 2: FTIR Spectra of Polyurethane, PUBC125, PUBC250, PUBC375

Figure 3: Rule of Mixture Models Overlapped with Experimental Data

a) with literature modulus value, b) calculated modulus value

Figure 4: DMA Graphs of Polyurethane and Polyurethane-Bacterial Cellulose Nanocomposites, a) The combined storage modulus curve for PU and nanocomposites b) tan delta curve for the neat polyurethane, c) tan delta curves for PU and nanocomposites

Figure 5: Transmission Electron Microscopy Images, a) PUBC125 b) PUBC125, higher magnification, c) PUBC250, d) PUBC375

Figure 6: Digital photos of transparent nanocomposite samples

Figure 7: AFM Image PUBC125 


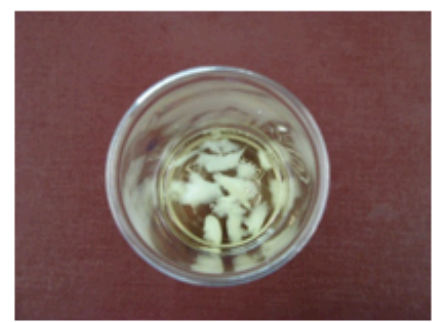

Polyol-Bacterial Cellulose

Before Mixing

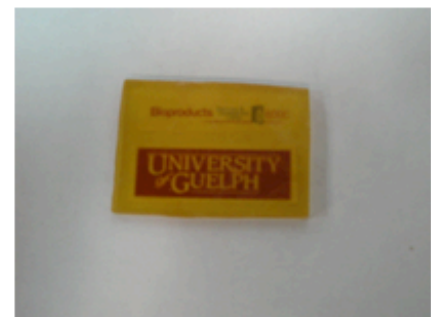

Polyurethane

Bacterial Cellulose

Nanocomposite

\section{Hand Mixing}

\begin{tabular}{c} 
Compression \\
Molding \\
\hline
\end{tabular}

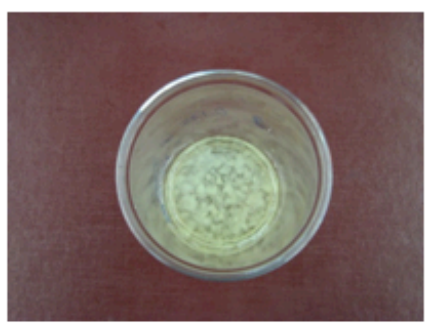

Polyol-Bacterial Cellulose After Hand Mixing $\downarrow$ Homogenizer

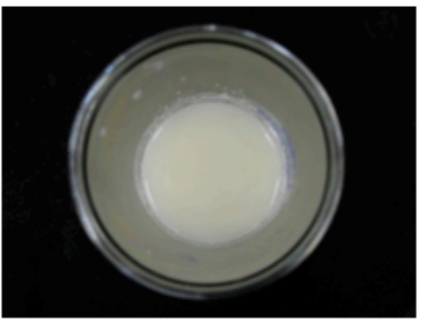

Polyol-Bacterial Cellulose After Homogenizer

Figure 1a 


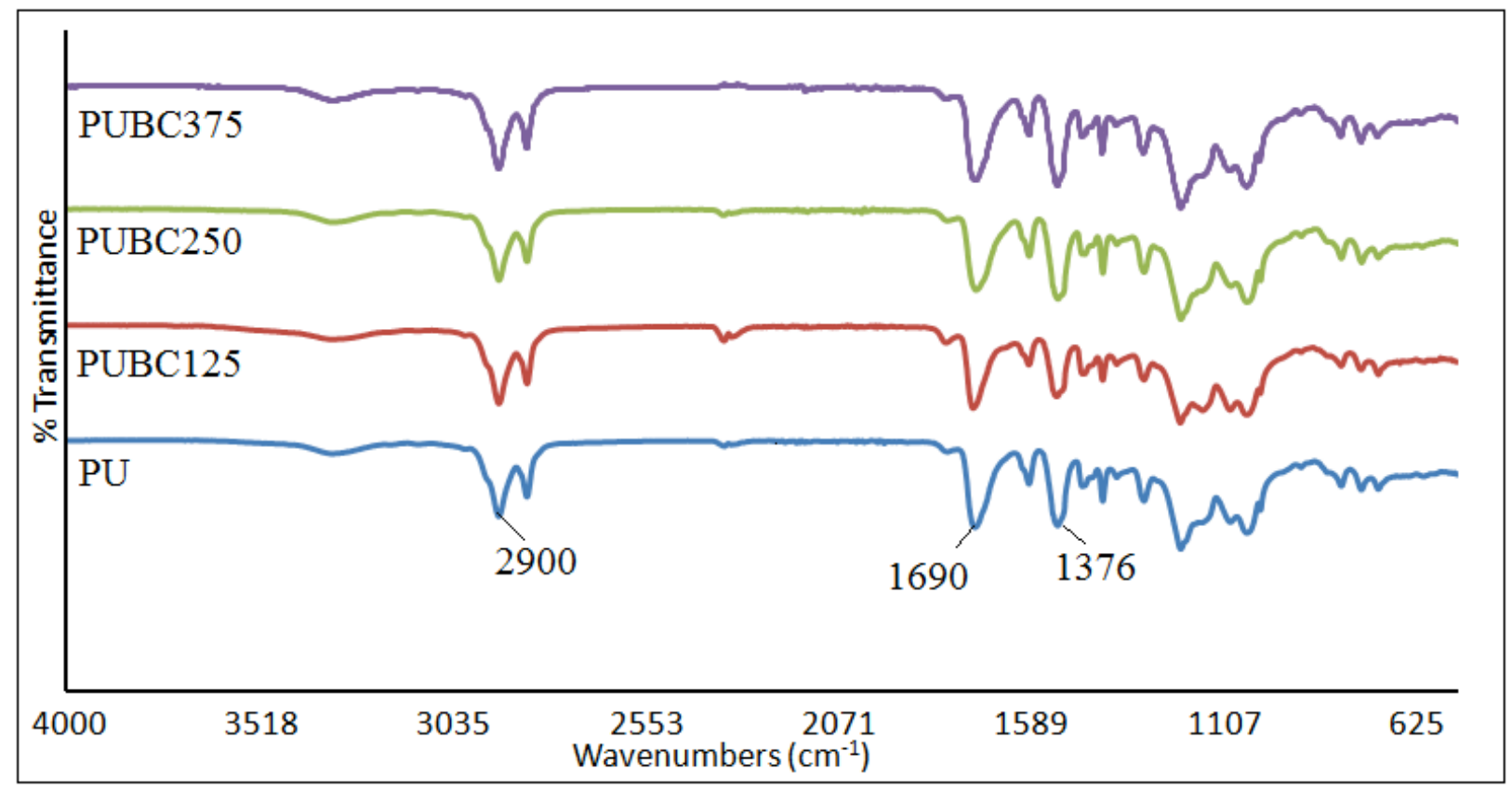

Figure 2 


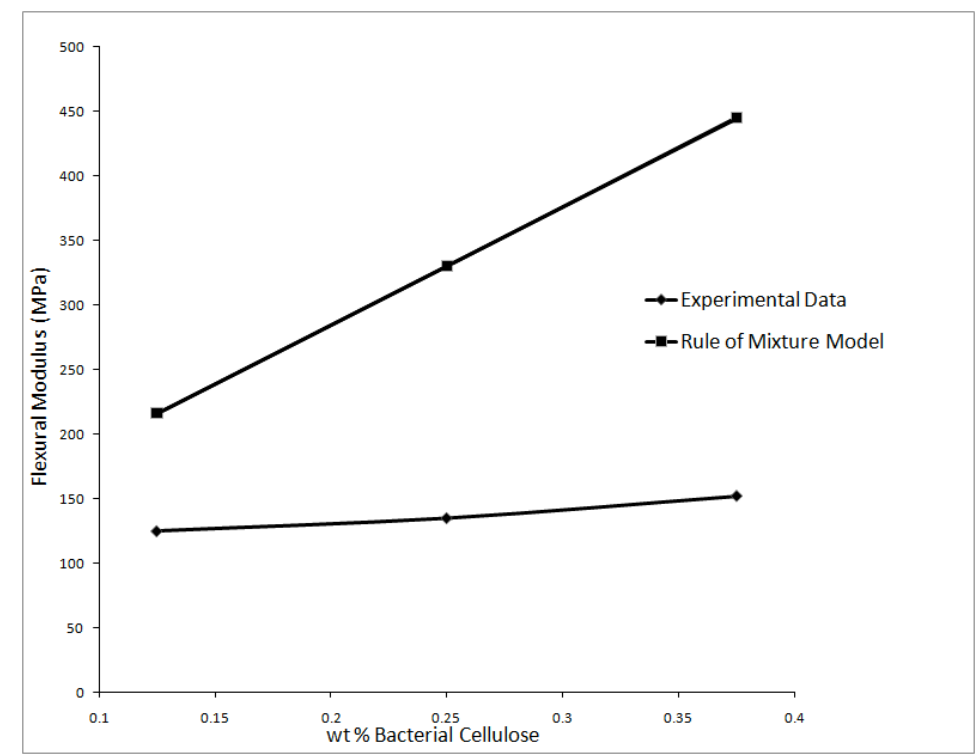

Figure $3 \mathrm{a}$

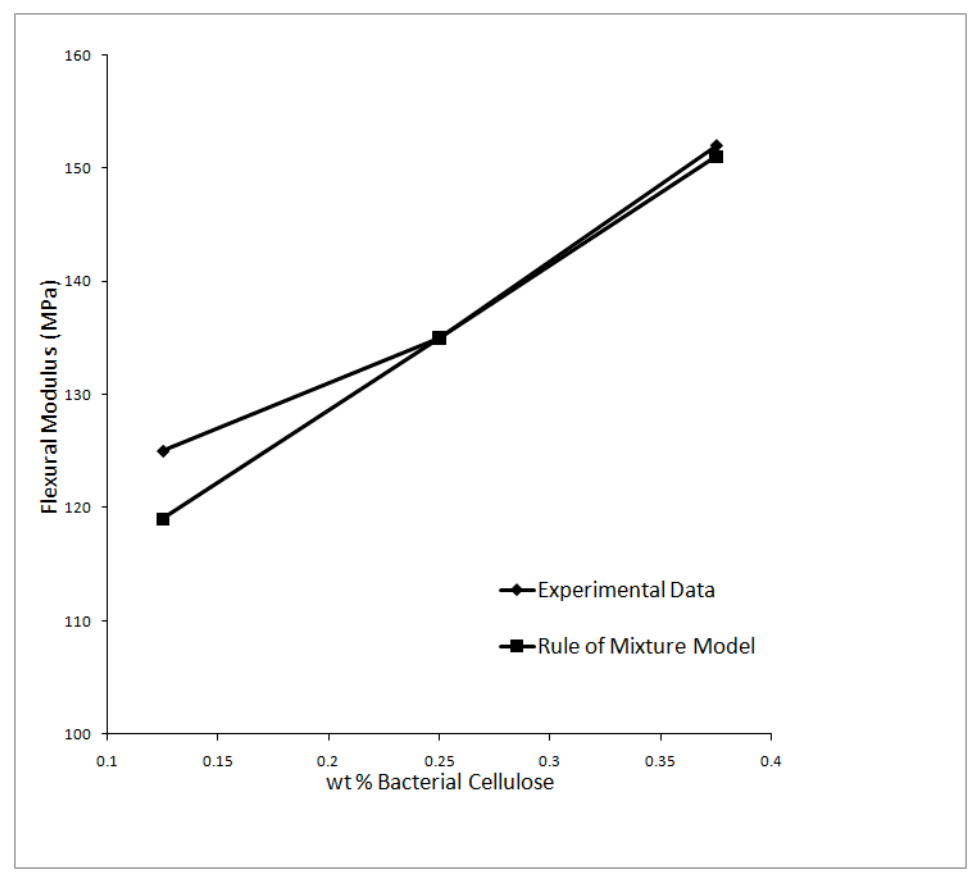

Figure $3 b$ 


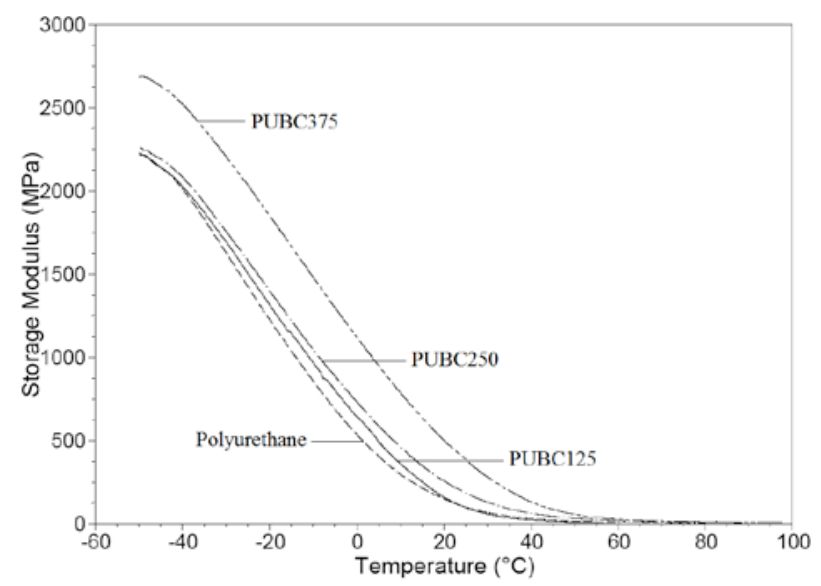

Figure 4a

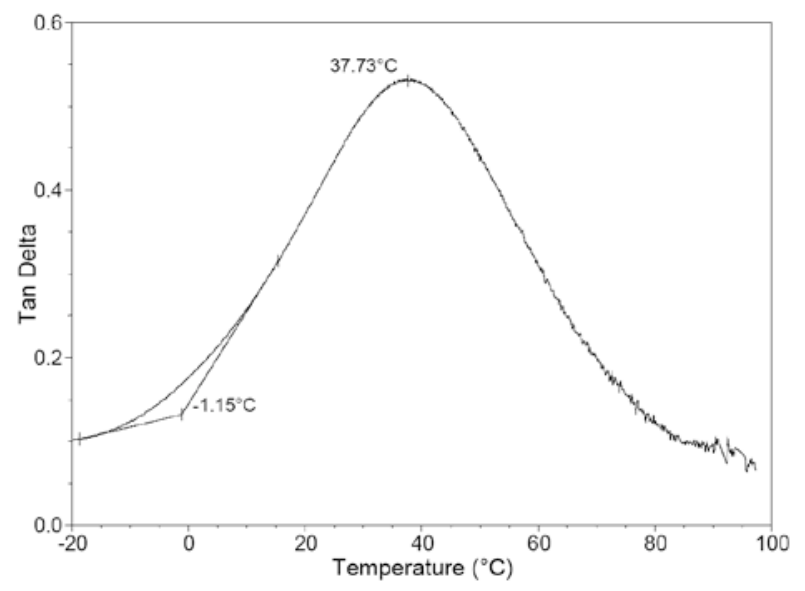

Figure 4b

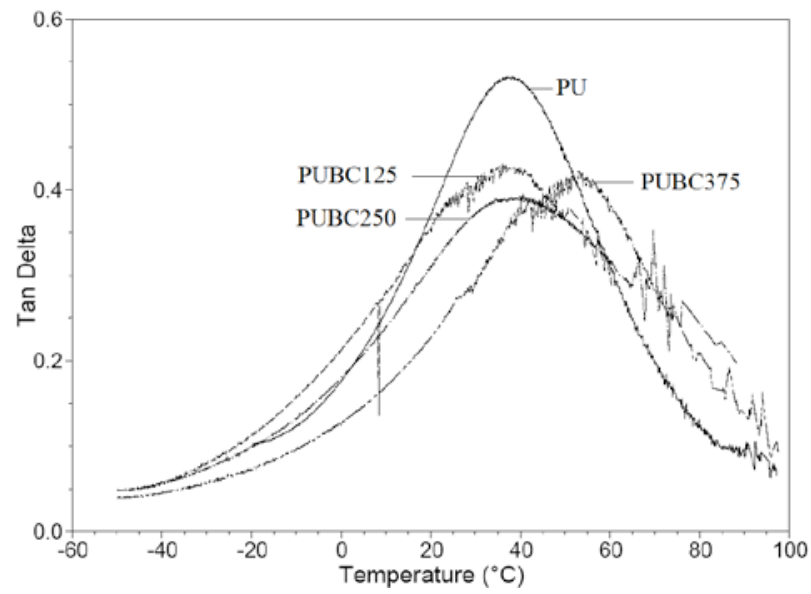

Figure 4c 


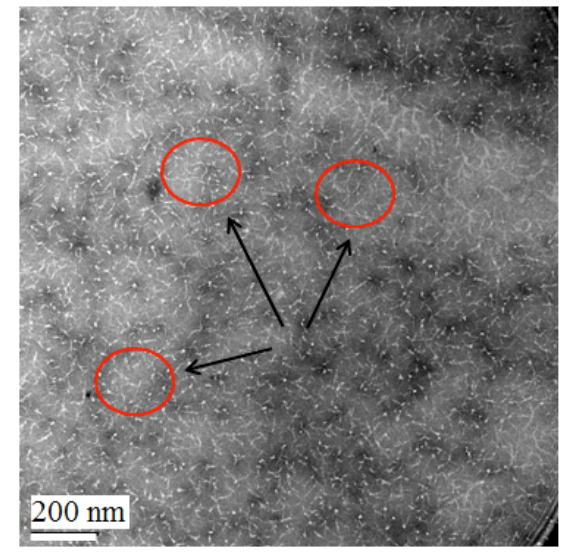

Figure 5a

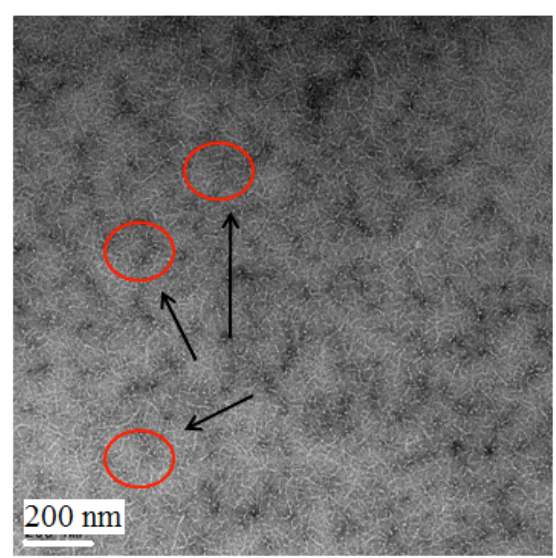

Figure 5c

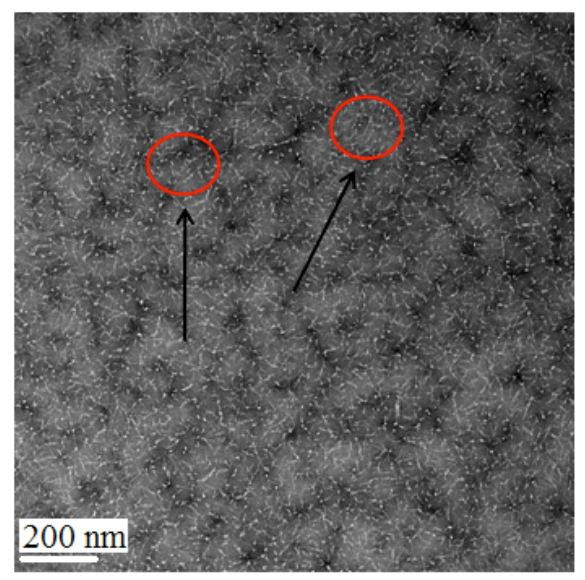

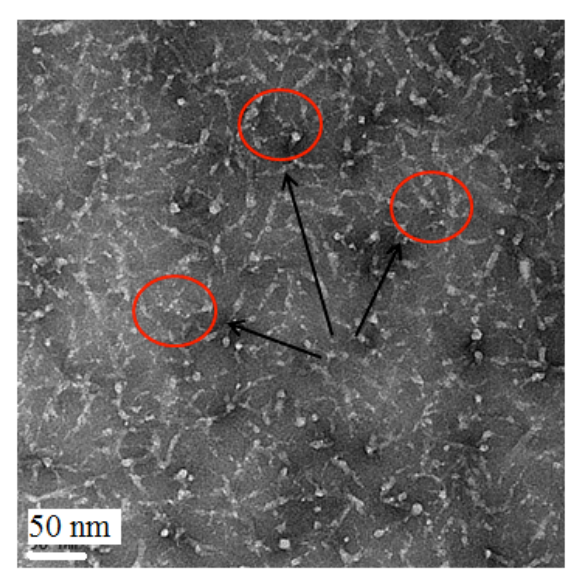

Figure 5b

\section{Figure 5d}



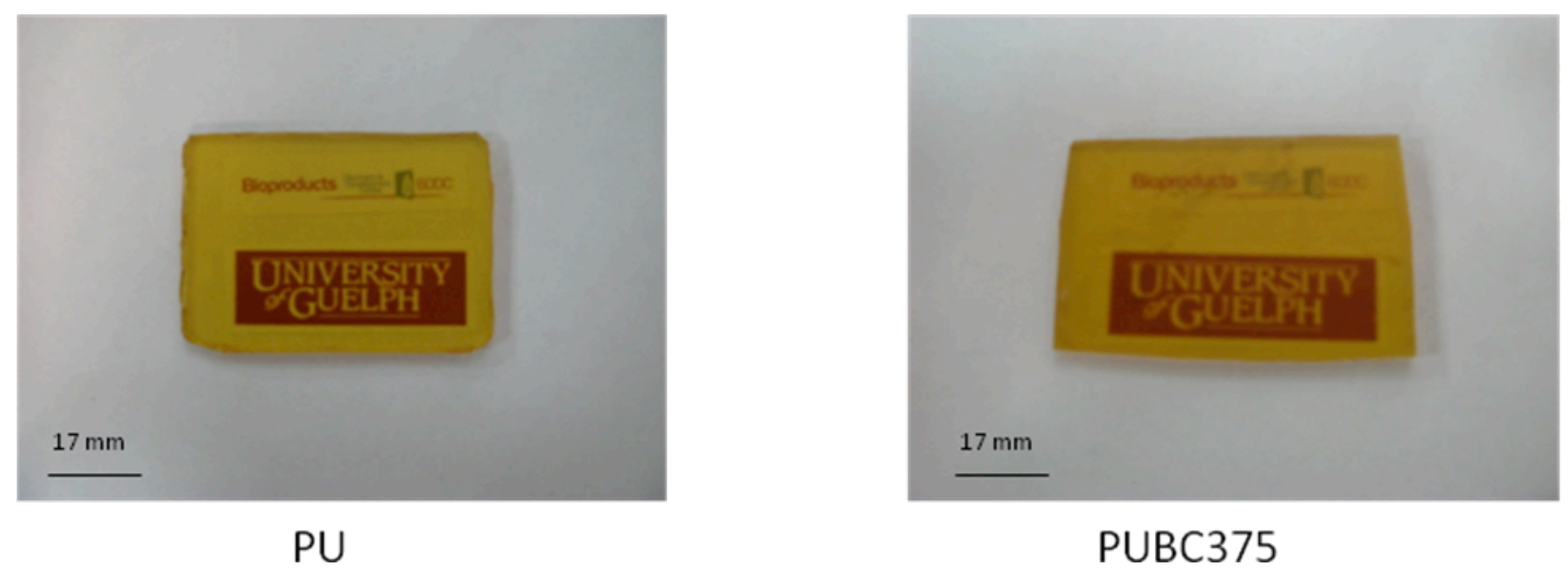

Figure 6 


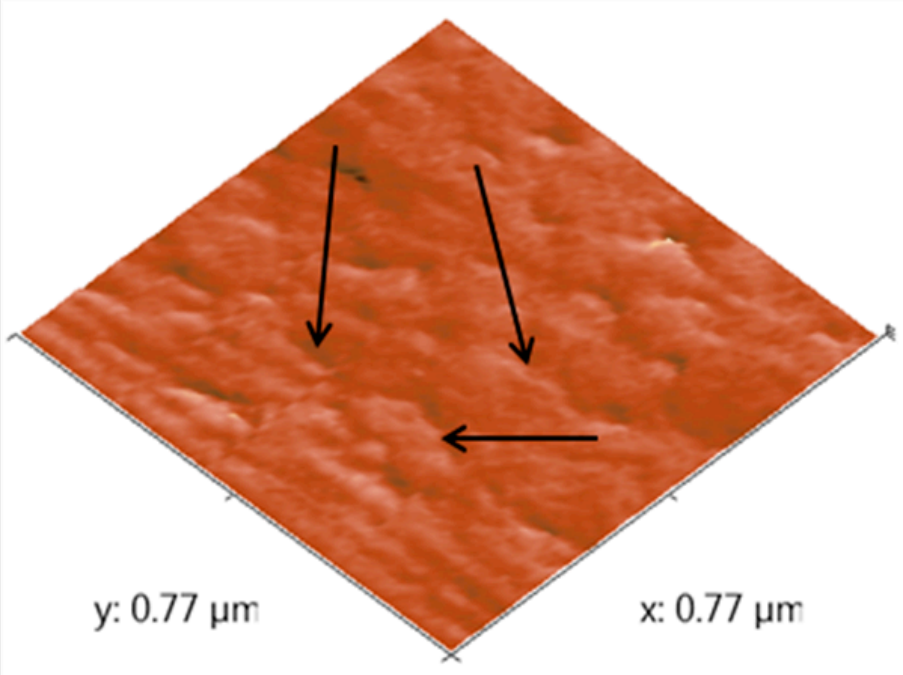

Figure 7 


\section{Table Captions}

Table 1: Bacterial cellulose nano-fibril loading in polyurethane matrices and their corresponding sample codes

Table 2: Flexural strength, flexural modulus and impact strength of polyurethane and polyurethane-bacterial cellulose nanocomposites 
Table 1

\begin{tabular}{cc}
\hline Material & Bacterial Cellulose Content (wt \%) \\
\hline PU & - \\
PUBC125 & 0.125 \\
PUBC250 & 0.250 \\
PUBC375 & 0.375 \\
\hline
\end{tabular}


Table 2

\begin{tabular}{cccc}
\hline Material & Flexural Strength $(\mathrm{MPa})$ & Flexural Modulus (MPa) & Impact Strength $(\mathrm{J} / \mathrm{m})$ \\
\hline PU & $3.03 \pm 0.62$ & $103.48 \pm 31.28$ & $82.76 \pm 5.73$ \\
PUBC125 & $3.81 \pm 0.22$ & $125.03 \pm 80.05$ & $52.08 \pm 2.38$ \\
PUBC250 & $6.00 \pm 0.21$ & $135.18 \pm 11.49$ & $48.29 \pm 8.97$ \\
PUBC375 & $5.28 \pm 0.30$ & $151.89 \pm 20.94$ & $42.13 \pm 3.04$ \\
\hline
\end{tabular}

